\title{
Family carers/next-of-kin perceptions of home-care technology: a review
}

This article was published in the following Dove Press journal:

Smart Homecare Technology and TeleHealth

14 May 2014

Number of times this article has been viewed

\author{
David G Smithard ${ }^{1,2}$ \\ 'Royal Victoria Hospital, Kent \\ Community Health NHS Trust, \\ Folkestone, UK; ${ }^{2}$ Department \\ of Electronics and Digital Arts, \\ University of Kent, Canterbury, UK
}

Correspondence: David G Smithard Royal Victoria Hospital, Kent Community Health NHS Trust, Radnor Park Avenue, Folkestone, Kent CTI 9 5BN, UK

$\mathrm{Tel}+44300425319$

Fax +44 300790021

\begin{abstract}
As the global population increases in age and the pressures on hospital resources increase, with a defined budget, the management of people in their own home environment is increasingly being accepted as a viable alternative to hospital admission. Evidence from the US and Australian health care systems has shown that acute care at home for older people is safe and the outcomes are at times better than when older people are admitted. Caring of people at home, particularly older people, puts an increased burden of expectation on the next of kin (family members); however, this burden appears to be offset by the reduction in the inconvenience that admission to hospital brings. In many cases, family members highlight the positives of home-based care, such as the convenience, increased contact, and in the case of people with long-term conditions, return of independence and socialization. However, we know little about the perceptions of family members to the ever-increasing possibilities of medically managing people at home, and future research needs to take this into account and to consider their views, as well as those of the people in receipt of care.
\end{abstract}

Keywords: telehealth, health care, acute care, hospital at home

\section{Introduction}

Telemedicine/telecare are not a new idea; healing at a distance has occurred since biblical times.

The global population is aging, with the ratio of young to old decreasing. ${ }^{1-5}$ As people age, they incur more illness, and an increasing number will have complex needs with more than one long-term condition. ${ }^{6}$ Long-term conditions consume $75 \%$ of the total health care budget. ${ }^{7}$

With the changing population demography and financial constraints, most health care systems have seen an increasing attendance at their emergency departments, with a consequent increase in hospital admissions, putting an undue amount of pressure on the diminishing resource of hospital beds. Older people do not want to go into hospital unless it is unavoidable, and there is an increasing recognition by health professionals and politicians that hospital is not the best place to care for older and frail individuals. Research in Australia and the US has shown a decrease in the incidence of delirium and mortality by providing acute care at home. ${ }^{8,9}$

Many older people with multiple comorbidities will be living on the edge of their physiological reserve, and any minor ailment may precipitate a crisis, resulting in a reduced ability to manage at home. Admission to hospital is frequently a necessity because of a lack of any alternative provision. Following a review, Yuginovich 
and Pearce noted that a third of hospital admissions in those $>75$ years could be avoided. ${ }^{10}$ Consequently, there is an increasing desire and need to develop and implement innovative and cost-effective ${ }^{11-15}$ alternatives to inpatient care (Figure 1). Telehealth is one way of delivering this model of care. A Veterans Health Administration study showed that by including telehealth in the veterans' care pathway, the number of hospital admissions was reduced by $19 \%$, readmissions by $25 \%$, and bed days by $25 \% .{ }^{16}$ Spain, the UK, and Australia, to name a few, have invested heavily into home-care technology (particularly telehealth). ${ }^{17}$

If medical care is going to be increasingly delivered in peoples' homes, health care commissioners and providers will have to consider the increased burden and expectation assumed by family carers. Family carers do not have medical training, are on call 24 hours a day, may not live in the same place as their relative, and may be in fulltime employment. This paper discusses the perceptions of and benefits to family carers that home-care technology brings.

\section{Background}

Home-care technology consists of a diverse array of devices of varying complexity (Table 1). At one extreme is the "humble walking stick and adapted cutlery," while at the other are complex "smart homes." Whatever the device is, and no matter how complex, they all have one aim: to enable the user of the technology to be safer and more independent. The evidence appears to support the premise that the more dependent the recipient of care, the more benefit they receive from technology. ${ }^{18}$

Home-care technology is often assumed to be the provision of teletechnology with assisted-living devices. The idea of electronic assistive technology providing independence to people with significant disability has been around for approximately 50 years (eg, http://www.possum.co.uk), and the ability to provide medical advice and support at a distance for even longer. In many countries, doctors have been providing care without seeing the patient, probably since time immemorial, and even more so since the advent of the telephone and more recently cellular telephone networks.

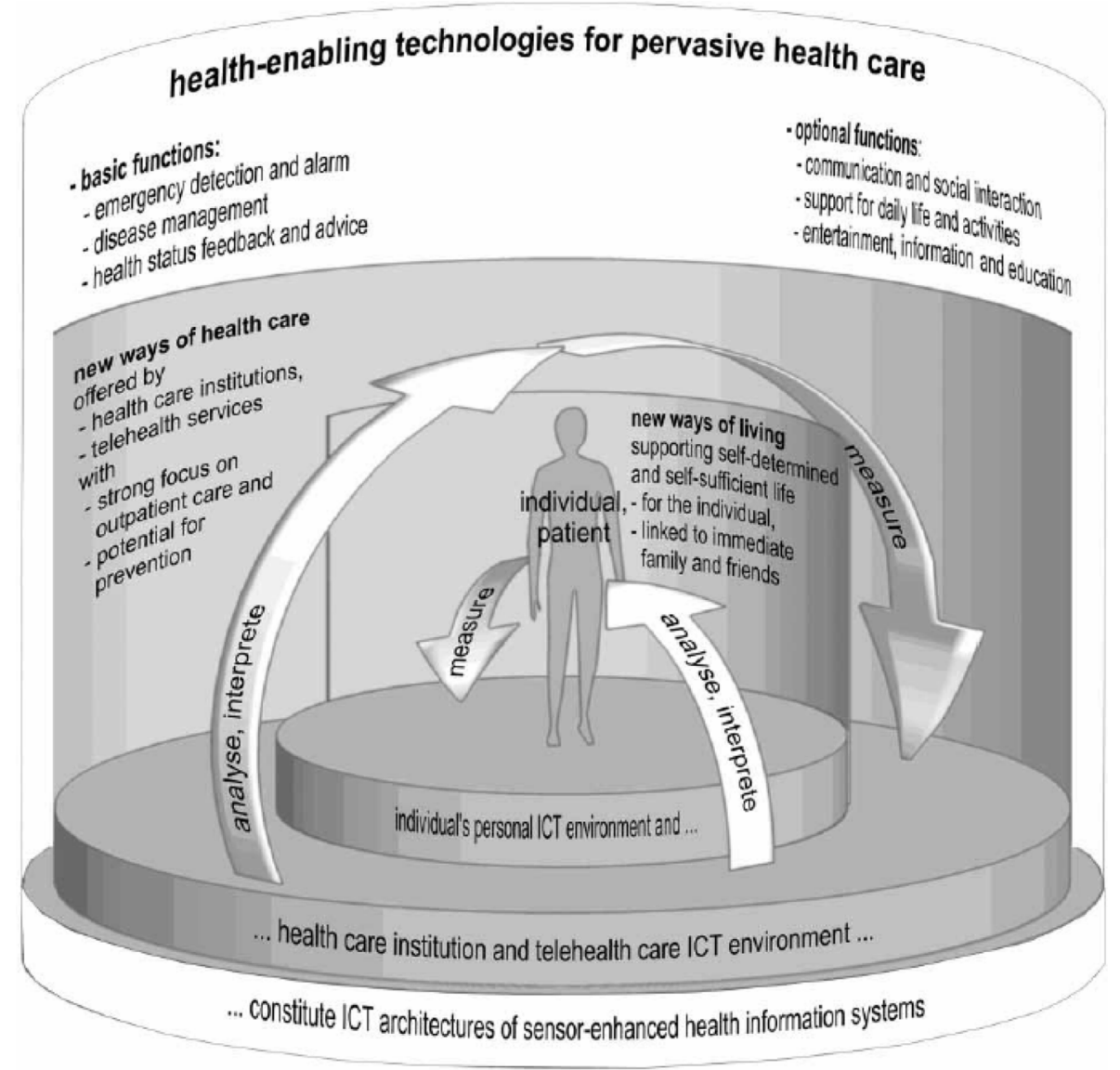

Figure I Health-enabling technologies for pervasive health care.

Note: Koch S, Marschollek M, Wolf KH, et al. On Health-enabling and Ambient-assistive Technologies. Methods Inf Med. 2009;48:29-37. ${ }^{6}$

Abbreviation: ICT, information and communications technology. 
Table I Examples of technology used in the home

\begin{tabular}{|c|c|c|c|}
\hline $\begin{array}{l}\text { Device } \\
\text { complexity }\end{array}$ & Low & Medium & High \\
\hline Examples & $\begin{array}{l}\text { Walking stick } \\
\text { Adapted } \\
\text { cutlery } \\
\text { Zimmer frame } \\
\text { Wheelchair }\end{array}$ & $\begin{array}{l}\text { Syringe driver } \\
\text { Nutrition pumps } \\
\text { Electric } \\
\text { wheelchair } \\
\text { Videophones } \\
\text { Life line } \\
\text { Wii } \\
\text { Mobile/cellular } \\
\text { telephone }\end{array}$ & $\begin{array}{l}\text { Physiological } \\
\text { monitoring } \\
\text { (telehealth) } \\
\text { GPS } \\
\text { Network hubs } \\
\text { Telehealth } \\
\text { with ECG, } \\
\text { ophthalmoscope } \\
\text { Telecare - } \\
\text { pressure sensors } \\
\text { Smart homes }\end{array}$ \\
\hline
\end{tabular}

Abbreviations: GPS, Global Positioning System; ECG, electrocardiogram.

The delivery of health care at a distance is an essential component of health care, particularly in rural and remote populations in many parts of the world. The Australian Royal Flying Doctor Service has been providing care to remote populations since the $1920 \mathrm{~s} .{ }^{19}$ Benschoter reported on a telepsychiatric service that has been up and running since $1967 .{ }^{20}$ In the $1970 \mathrm{~s}$, Germany introduced a phone chain as a way of monitoring and checking on people, and as computers have become more available, the system using broadband and video links is taking over. This has created problems of accessibility due to lack of system coverage. ${ }^{21}$ Even with this long history, the development of systems has focused on the delivery of care and not the caregiver. $^{22}$

\section{Teletechnology}

Teletechnology, like most things, is beset by difficulties of definition. Within community settings, the major divide is between that provided for social care (telecare) and that provided for health reasons (telehealth). Often, the reality is that people are receiving a combination of the two, and in fact they are just the opposite ends of a spectrum of care.

\section{Terminology}

Telecare is the provision of a system of warning/responsive devices to provide reassurance and rapid response to people, usually in their own homes. This service is frequently provided by social care providers and consists of pressure sensors, Life Line, infrared beams, door-opening sensors, and (controversially) Global Positioning System (GPS) devices. ${ }^{23}$

Telehealth, like most health care, is beset by terminology. Over the years, various terms have appeared (telemedicine, telehealth, ehealth, telehomecare, and homecare technology), have become blurred, and in most instances the terms are interchangeable. A definition that encompasses them all is: a form of medicine that permits/supports the clinical care of a patient, where the various professionals and the patient may not be in the same physical location. ${ }^{10,24-31}$

The services provided can be low-tech, in the provision of a videophone to permit two-way conversations between patients and medical staff/nurses, or can be far more intensive, with frequent monitoring of patients in the acute setting with the ability to use ophthalmoscopes, stethoscopes, oxygen monitoring, temperature, blood pressure, and electrocardiograms (Figure 2). ${ }^{30}$

The main functions/roles of home-care technology (including smart homes) are documented in Table 2. The three main purposes for the provision of home-care technology are safety, quality, and efficient use of time/resources. ${ }^{32-35}$ Community care and community health care is extremely resource-intensive, and consequently it is essential that all stakeholders are signed up to the model of care, including the recipient of the care and their formal and informal carers (family carers).

\section{Health care resistance}

It is an interesting conundrum that health care workers, and doctors in particular, recognize the need for technology, yet when the use of technology is suggested to manage people in the community, all sorts of barriers arise. It is not uncommon to see the use of simple devices in the community setting (pumps to deliver enteral/parenteral nutrition, syringe drivers for medication, non-invasive positive pressure ventilation, hoists, and walking frames; Table 1), but it is less common generally to find the use of ventilators, robots, robotic suits, etc. ${ }^{34}$

Irrespective of what the terminology is and whether it is agreed on or not, the crucial factor is that the patient and their family/next of kin need to be accepting of and agreeing to use the provided or utilized technology, particularly as each person involved may have different expectations (objectives/ outcomes) and objections regarding the system..$^{36,37}$

\section{Next-of-kin/family carer perceptions}

There are many studies that have shown that the inclusion of home-care technology in a clinical pathway is as effective as hospital-based care for the appropriate patient. It is not a panacea, but provides an effective alternative in many circumstances (acute care, exacerbations of long-term conditions, postoperative recovery, rehabilitation). These studies have provided a wealth of evidence that the patient 


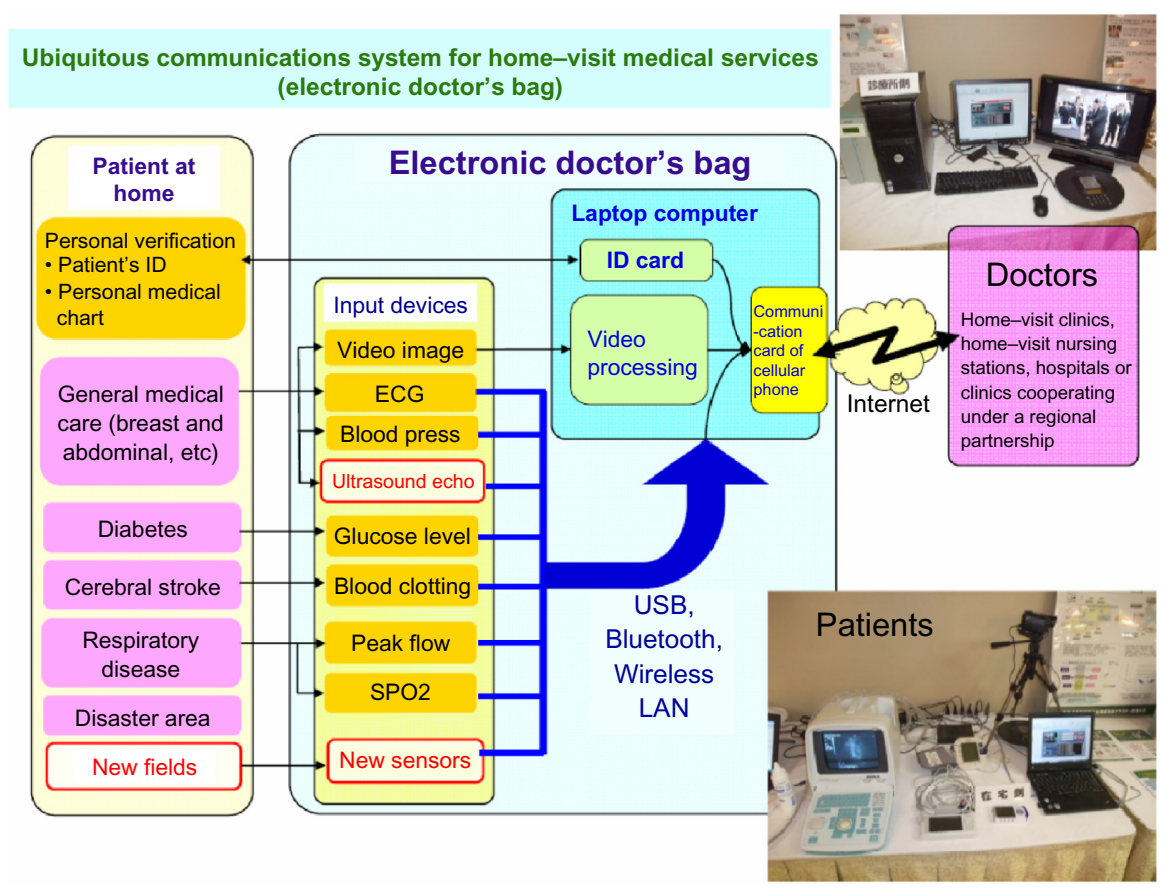

Figure 2 Framework of the "electronic doctor's bag."

Note: () 2010 IEEE. Reprinted, with permission, from Yoshizawa M, Yambe T, Konno S, et al. A mobile communications system for home-visit medical services: the Electronic Doctor's Bag. Conf Proc IEEE Eng Med Biol Soc. 2010;20 10:5496-5499. ${ }^{30}$

Abbreviations: ECG, electrocardiogram; USB, Universal Serial Bus; LAN, local area network; press, pressure.

is satisfied with the care, with the flexibility it provides, and the increased access to clinical staff. ${ }^{14,38-42}$

Next-of-kin (family carers) views/perceptions of homecare technology (telehealth/telecare) over the years have generally been poorly documented (with only $5 \%$ of studies in 2001 studying carer perceptions). ${ }^{43}$ Many studies that have investigated the response/perceptions of patients and clinical staff to the use of the technology have failed to document prospectively the benefits accrued to the carers, even though it has been acknowledged that care and technology at home changes family dynamics. ${ }^{6,44}$

Those studies that have collected data have frequently used a narrative or anecdotal methodology. ${ }^{42,44,45}$ Despite this, the general consensus is that family carers are satisfied with home-care technology, finding it useful and in some cases life-changing. ${ }^{46}$ In a study using remote cardiac monitoring to detect silent myocardial infarction in a nursing home population, Clarke et al reported statements supporting the use of technology and that it provided reassurance to

Table 2 Function of each technology system

\begin{tabular}{llll}
\hline System & Telecare & Telehealth & Smart homes \\
\hline & Safety & Diagnosis & Safety \\
& Support carer & Management & Continuous \\
& Reduce anxiety & Education & monitoring \\
& Monitoring movement & & \\
\hline
\end{tabular}

the relatives. ${ }^{44}$ More recently, the Royal College of Physicians (London) report Care Closer to Home commented that carers (informal) were more satisfied with the use of telehealth, but could not provide any evidence or robust data to support the statement. ${ }^{47,48}$ Clark and Goodwin echo the statement of the Royal College of Physicians. ${ }^{45}$ The benefits of homecare technology may need unpicking, much like the black box of stroke-unit care.

The benefits that family carers receive from home-care technology can be classified as direct or indirect, ie, the benefits accrued have been secondary to the support of the person being cared for.

Rialle et al studied carers of those with Alzheimer's dementia, of which $48 \%$ were the spouse, $26 \%$ siblings, and $6 \%$ other relatives, and enquired as to which device would be the most useful, including the use of videoconferencing and a tracking device for the patient. Views expressed were spread across both extremes: those who found the support useful, and those who found no use for it (eg, as they could not get the time to access the videoconferencing) ${ }^{49}$ The tracking device was the most popular (women and younger age, $P=0.0025$ ), with videoconferencing being the second most popular device (no predominance with age or sex). Variance analysis found that there was a significant relationship between the age of the carer and appreciation of the technology $(P=0.0001){ }^{49}$ In a study of informal care of people with serious mental 
illness, Giger reported a perceived usefulness for in-home teletechnology, but again there were those that did not see (or appear to gain) much benefit from it. ${ }^{50}$ The more involved a carer was, the more likely they were to access information technology, (odds ratio 1.88 [95\% confidence interval 1.013.50 ] versus 3.7 [1.67-8.45]). Interestingly, middle-income carers were least likely to use the equipment. The results were more impressive for those family carers who were not close/ living with the receiver of care. ${ }^{51} \mathrm{In}$ his $\mathrm{PhD}$ thesis, Giger discussed the possibility of a model for predicting the uptake of telehealth, by taking together the perception of usefulness and subtracting the ease of use. ${ }^{50}$

These benefits can be classed as direct, ie, the telehomecare input was for direct support of the carer (next of kin) rather than the one being cared for.

\section{Indirect benefit}

Indirect benefit that accrues to the family carer can be defined as that which is secondary to the benefits afforded to the person receiving care. In her report of the Dorset evaluation, Wallis states that family members report "getting their life back" and "being more relaxed." Part of this was knowing that they had support and backup from the control/call centers. ${ }^{52}$ Keeping-Burke et al found that 1 week of daily visits using audiovisual nursing reduced anxiety levels ( $P=0.003)$, uncertainty $(P=0.02)$, and depression $(P=0.03) .{ }^{53}$ In a randomized controlled study of telehealth in the postacute phase of care, Cartwright et al found that informal carers thought that telehealth had a positive impact and that the majority were in favor of it as a system to support the care of their families. ${ }^{17}$ One comment was that they needed to take less time off work, were less likely to be late, and less likely to take time off sick. Lind et al reported that the family caregivers liked the flexibility that telehealth delivered. ${ }^{54}$ Soar and Seo reported that by using teletechnology to monitor vital signs, medical staff could prioritize house visits. ${ }^{55}$

Magnusson and Hanson pointed out the secondary gain from the use of information technology to support the patient. ${ }^{56}$ Bank et al studied informal carers (spouses, siblings, children) of people with dementia, and $68 \%$ of those who took part in the study reported teletechnology helped them care for their family member as well as provide them personally with support. ${ }^{57}$ This satisfaction persisted, even though there was a perceived increase in burden and an upheaval in day-to-day activities, and families felt positive toward this model of care. ${ }^{15}$

Similarly, where questions have been asked regarding telehealth as a means of managing a relative, responses have been positive, despite the added pressures and the degree of uncertainty that has to be accepted. Relief was expressed that journeys to clinics did not have to be undertaken, with the consequent absence of any problems with parking. Also, the time spent with nursing staff via the videophone was greater and better focused than if they had been on the ward. Privacy and dignity were also improved. Magnusson and Hanson ${ }^{56}$ noticed that carer confidence and knowledge was increased by the use of telehealth. Topo et al noted that family members were more independent and had more freedom with the use of telehealth. ${ }^{58,59}$ Reviewing the results of hospital-in-thehome services for a Cochrane review, Leff noted that family members were satisfied with treatment at home, ${ }^{14}$ though patients were more so, and that these benefits may persist for some time. ${ }^{41}$

Kent County Council ${ }^{13}$ was one of the first organizations to push for a model of telehealth in the UK (Kent telehealth pilot). A small study of 250 people, whilst not directly studying family members, received comments that they found that telehealth provided peace of mind and "a life-changing experience" and that "they were over the moon." Despite fears that family carers would not want the technology, the converse was noted. In one case, where the patient died, the family were still very positive about the care provided via telehealth. Marineau reported that family carers enjoyed the support that telehealth offered and they had better control and freedom, but this was not explored further. ${ }^{60}$

Where patients are seriously physically ill and have multiple morbidities, the family members providing care can become significantly socially isolated, with a resulting deterioration in their own physical and mental health. The use of telehealth in this situation, either directed to the caregiver or indirectly, can reduce carer anxiety, reduce stress, and increase independence by providing a safety net. ${ }^{61-63}$

\section{Direct carer benefit}

Direct benefit is the benefit accrued to the family carer directly by the use of home-care technology. This is demonstrated by the use of technology to provide education or peer/professional support to them. Where studies have examined the role of telehealth in educating the carer, general satisfaction has been expressed both with the training provided and the ability to link with other carers in a mutually supportive way.

Marineau, ${ }^{60}$ Winterton and Warburton ${ }^{64}$ and Van Ast and Larson $^{65}$ reported on the use of telehealth to provide teaching/ education for family members and social support. There was a positive response to this. Studies have found that families as well as professionals accepted the role of telepsychiatry for the 
reasons given earlier, and caregivers felt empowered because they knew that there was help at the end of a telephone. ${ }^{46,66}$

Studying renal patients in Finland for a PhD thesis, Asteljoki found that people/carers enjoyed the peer support/ discussion groups, as they found them useful. ${ }^{67}$ However, where a similar system was being used for families caring for people with dementia, carers would be more relaxed with the system if the person being cared for was distracted. ${ }^{64}$

Sävenstedt ${ }^{68}$ Lutz and Young ${ }^{69}$ and Buckley et a ${ }^{70}$ studied caregivers of stroke patients (including family carers), and found that web-based support was received positively. With telephone interviews, there were better scores on the Short Form (36) Health Survey, improved problem-solving skills, and less depression compared to controls.

Wright et al found that telehealth improved the mental health of carers. ${ }^{61}$ Concerns were around personal safety, home security, learning how to use the equipment, and the carers' own health needs. In general, they were enthusiastic and found it reduced isolation, allowing contact with people in a similar situation.

\section{Perceptions in general}

Often, the satisfaction in care and the benefit perceived will depend on the community being studied, with those in more remote areas being more satisfied with the improved care being offered. ${ }^{71}$ Roberts et al studied the provision of touch-screen pods to provide psychiatric services to a small population in Argyll and Bute. ${ }^{40} \mathrm{~A}$ high degree of satisfaction was reported in this model of care: the telepsychiatry service was a welcome service, and perceived usefulness and attitude to the service depends on the closeness of the family member, ie, the further away they lived, the more useful they found the system. ${ }^{72}$

\section{Future directions}

What does the future hold? It is possible that there will be a revolution using devices that people already have, making use of mobile/cellular phones (web/cloud systems to allow almost continuous linkage between families, those needing care and professionals). ${ }^{73}$

Unobtrusive devices are being developed to monitor movements, but also to detect and relay physiological variables. As devices become smaller and the possibilities of monitoring increase, any further research must investigate the perceptions of those doing the caring and the effects on them.

\section{Concerns regarding the use of home-care technology}

The concerns raised will depend on the technology used. In the case of home ventilation for children, Quint et al found in a small study that the longer the need for carer input continued, the less able the primary carer was to cope with stress when compared to their spouse. ${ }^{75}$

Despite the clinical benefits that care at home realizes, not everyone is willing to accept the technology. The main reasons for this, from both carers and recipients of care, are concerns over dignity and privacy. ${ }^{33,75,76}$ Lehoux has raised the concern that to be able to use a device, ${ }^{76}$ no matter how simple, if a person does not understand the concept of what they are doing, then it is unlikely the device will be used. Despite the obvious benefits from accessibility, ${ }^{77}$ the lack of traveling and reduced time lost, Rietdijk et al report that face to face care is still the preferred method by $38 \%$ of carers; however, the benefits that telehealth brings were accepted by all. ${ }^{78}$

There has been a concern that older people are unable to adapt or learn to use the technology. This has not been proven to be the case. Increasing numbers of older people are taking to the Internet, have smart mobile phones and televisions, and are increasingly communicating across the web (many carers are over the age of 70 years). These "silver surfers" are increasingly a force to be reckoned with. Many of the problems have arisen because of inadequate explanation. ${ }^{42}$

Concerns have been raised by several authors that the use of home-care technology is intrusive, potentially disruptive, stigmatizing, unwelcome, disempowering, and the medicalization of life..$^{78-80}$

What was noticed in some of the acute-care studies was that nonenrollment had been due to carer resistance, and this was also found in the Whole System Demonstrator study. ${ }^{81}$ Reasons included safety, invasion of privacy, and dignity. Evaluative studies have reported that service users found some devices intrusive, more because of the risk of alarms going off during normal day-to-day activities, ${ }^{42,52}$ but the benefits were understood.

GPS devices are available in mobile telephones or in wrist devices (looking like wristwatches). In a case of Alzheimer's dementia, a tracking device was felt to be satisfactory, though there were divergent views among family carers. ${ }^{49}$ There may be increasing ethical and moral concerns as technology advances, and the ability to either implant, wear, or embed devices in clothing, could result in people being monitored inappropriately. A study in Surrey, UK, showed that service 
users were more concerned by closed-circuit TV monitoring in their own home than any embedded device. ${ }^{81}$

\section{Conclusion}

Home-care technology has been available in one shape or form for nearly 100 years. The general perceptions of the next of kin are positive, with many expressing relief at getting their life back, or knowing that someone was on hand, giving them peace of mind. Some reservations have been raised around the invasion of privacy and dignity, but these are less of a problem than the benefits accrued. Where technology has been used to support the family carer directly, there appears to be an inverse relationship, in that the further away from support (peer or professional), the more benefit was perceived.

The present home-care technology that is being used is becoming more complex, with the possibility of networked systems and "smart homes" that would allow continuous 24-hour monitoring of peoples' movements as well as their vital medical signs. Concerns over the ethics and worries regarding "Big Brother and Nineteen Eighty-Four ${ }^{82}$ " will need to be discussed. However, evidence would suggest that service users will be positive, whereas others may have considerable reservations.

\section{Disclosure}

I received no monetary payment in kind from any pharmaceutical or device-based company. I have received expenses from Nestle Health Science. I am the president of the UK Swallowing Research Group and a member of the European Society for Swallowing Disorders.

\section{References}

1. United Nations. World Population to 2300. New York: UN; 2004.

2. Lanzieri G. Long-term population projections at national level. Available from: http://epp.eurostat.ec.europa.eu/cache/ITY_OFFPUB/KS-NK-06003/EN/KS-NK-06-003-EN.PDF. Accessed November 27, 2013.

3. United Nations. World Population Ageing 2007. New York: UN; 2007.

4. Marschollek M, Wolf KH, Bott OJ, Howe J, Haux R. Predictions for Epidemiologic indicators of age-related diseases and implications for the development of health-enabling technologies. Commun Comput Inf Sci. 2008;11:253-260.

5. Mathers CD, Loncar D. Projections of global mortality and burden of disease from 2002 to 2030. PLoS Med. 2006;3:e442.

6. Koch S, Marschollek, Wolf KH, Plischke, Haux R. On health-enabling and ambient-assistive technologies. What has been achieved and where do we have to go? Methods Inf Med. 2009;48:29-37.

7. Moore KL, Boscardin WJ, Steinman MA, Schwartz JB. Age and sex variation in prevalence of chronic medical conditions in older residents of US nursing homes. J Am Geriatr Soc. 2012;60:756-784.

8. Caplan GA, Coconis J, Board N, Sayers A, Woods J. Does home treatment affect delirium? A randomised controlled trial of rehabilitation of elderly and care at home or usual treatment (the REACH-OUT trial). Age Ageing. 2006;35:53-60.
9. Boult C, Green AF, Boult LB, Pacala JT, Snyder C, Leff B. Successful models of comprehensive care of older adults with chronic conditions. Evidence for the Institute of Medicines "Retooling for an Aging America" report. J Am Ger Soc. 2009;57:2328-2337.

10. Yuginovich T, Pearce S. Experiences of consumers over 65, their carers and health professionals in the community in relation to their use of assistive technology: a comprehensive systematic review. 2011. Available from: http://www.joannabriggslibrary.org/jbilibrary/index. php/jbisrir/article/view/415. Accessed November 27, 2013.

11. Chan M, Campo E, Estève D, Fourniols JY. Smart homes - current features and future perspectives. Maturitas. 2009;64:90-97.

12. Andrade MV, Maia AC, Cardoso CS, Alkmim MB, Ribeiro AL. Cost-benefit of the telecardiology service in the state of Minas Gerais: Minas Telecardio Project. Arq Bras Cardiol. 2011;97:307-316.

13. Alaszewski A, Cappello R. Piloting Telecare in Kent County Council: The Key Lessons. Canterbury (UK): University of Kent; 2006.

14. Leff B. Defining and disseminating the hospital-at-home model. CMAJ. 2009;180:156-157.

15. Shepperd S, Harwood D, Jenkinson C, Gray A, Vessey M, Morgan P. Randomised controlled trial comparing hospital at home care with inpatient hospital care. I: three month follow up of health outcomes. BMJ. 1998;316:1786-1791.

16. Darkins A, Ryan P, Kobb R, et al. Care Coordination/Home Telehealth: the systematic implementation of health informatics, home telehealth, and disease management to support the care of veteran patients with chronic conditions. Telemed J E Health. 2008;14:1118-1126.

17. Cartwright C, Wade R, Shaw K. The impact of telehealth and telecare on clients of the transition care program (TCP). 2011. Available from: http:// www.bcs.org.au/site/DefaultSite/filesystem/documents/About\%20BCS/ Resources/TRP\%20-\%20The \%20Impact $\% 20$ of $\% 20$ Telehealth $\% 20$ and $\% 20$ Telecare $\% 20$ on $\% 20$ Clients $\% 20$ of $\% 20$ the $\% 20$ Transition $\% 20$ Care\%20Program\%20Report\%20-\%20May\%202011.pdf. Accessed November 27, 2013.

18. Agree EM, Freedman VA. A quality-of-life scale for assistive technology: results of a pilot study of aging and technology. Phys Ther. 2011;91:1780-1788.

19. Moffat J, Ely DS. The reported benefits of telehealth for rural Australians. Aust Health Rev. 2010;34:276-281.

20. Benschoter RA. V. Television. Multi-purpose television. Ann New York Acad Sci. 1967;142:471-478.

21. Paulus W, Hilbert J, Potratz W. ICT for housing. In: Cabrera M, Malanowski N, editors. Information and Communication Technologies for Active Ageing: Opportunities and Challenges for the European Union. Amsterdam: IOS; 2009.

22. Consolvo S, Roessler P, Shelton BE, LaMarca A, Schilit B, Bly S Technology for care networks of elders. IEEE Pervasive Comput. 2004;3:22-29.

23. Wade R, Shaw K, Cartwright C. Factors affecting provision of successful monitoring in home telehealth. Gerontology. 2012;58:371-377.

24. Field MJ, Grigsby J. Telemedicine and remote patient monitoring. JAMA. 2002;288:423-425.

25. Glueckauf RL, Ketterson TU. Telehealth interventions for individuals with chronic illness: research review and implications for practice. Prof Psychol Res Pr. 2004;35:615-627.

26. Glueckauf RL, Ketterson TU, Loomis JS, Dages P. Online support and education for dementia caregivers: overview, utilization, and initial program evaluation. Telemed J E Health. 2004;10:223-232.

27. Nickelson DW. Telehealth and the evolving health care system: strategic opportunities for professional psychology. Prof Psychol Res Pr. 1998;26:527-535.

28. Lehmkuhl HD, Storch EA, Cammarata C, et al. Telehealth behavior therapy for the management of type 1 diabetes in adolescents. J Diabetes Sci Technol. 2010;4:199-208.

29. Daly JM, Jogerst G, Park JY, Kang YD, Bae T. A nursing home telehealth system: keeping residents connected. J Gerontol Nurs. 2005;31: $46-51$. 
30. Yoshizawa M, Yambe T, Konno S, et al. A mobile communications system for home-visit medical services: the Electronic Doctor's Bag. Conf Proc IEEE Eng Med Biol Soc. 2010;2010:5496-5499.

31. Eysenbach G. What is e-health? J Med Internet Res. 2001;3:E20.

32. Burgiss S, Dimmock SL. Telehealth in home health care. In: Armstrong ML, Frueh S, editors. Telecommunications for Nurses: Providing Successful Distance Education and Telehealth. 2nd ed. New York: Springer; 2002.

33. Van Halteren A, Konstantas D, Bults R. et al. MobiHealth: ambulant patient monitoring over next generation public wireless networks. Stud Health Technol Inform. 2004;106:107-122.

34. Arcelus A, Jones MH, Goubran R, Knoefel R. Integration of smart home technologies in health monitoring systems for the elderly. Poster presented at: 21st International Conference on Advanced Networking and Applications Workshops/Symposia; May 21-23, 2007; Niagara Falls (ON).

35. Åkesson K, Saveman BI, Nilsson G. Health care consumers' experiences of information communication technology - a summary of literature. Int J Med Inform. 2007;76:633-645.

36. McGee-Lennon MR. Requirements engineering for home care technology. Proceedings of the SIGGHI Conference on human factors in computing systems. CHI Conf Proc. 2008:1439-1442.

37. Clark J, McGee-Lennon MR. A stakeholder-centred exploration of the current barriers to the uptake of home care technology in the UK. J Assist Technol. 2011;5:12-25.

38. Car J, Huckvale K, Hermens H. Telehealth for long-term conditions. BMJ. 2012;344:e4201.

39. Guillén S, Arredondo MT, Traver V, et al. User satisfaction with home telecare based on broadband communication. J Telemed Telecare. 2002;8:81-90.

40. Roberts A, Godden DJ, Garrett L. Evaluation of the Use of TeleHealth in Argyll and Bute. Inverness: UHI Millennium Institute; 2010.

41. Jia H, Chuang HC, Wu SS, Wang X, Chumbler NR. Long-term effect of home telehealth services on preventable hospitalization use. J Rehabil Res Dev. 2009;46:557-566.

42. Horton K, Anderson J. Surrey Preventative Technologies Grant Project Evaluation. Kingston upon Thames (UK): Surrey County Council; 2007.

43. Egger M, Smith GD, Altman DG, editors. Systematic Reviews in Health Care: Meta-analysis in Context. London: BMJ Group; 2001.

44. Clarke M, Bratan T, Kulkarni S, Jones R. The impact of remote patient monitoring in managing silent myocardial infarction in a residential home setting. Anadolu Kardiyol Derg. 2007;7 Suppl 1:186-188.

45. Clark M, Goodwin N. Sustaining innovation in telehealth and telecare. 2010. Available from: http://www.kingsfund.org.uk/sites/files/kf/ Sustaining-innovation-telehealth-telecare-wsdan-mike-clark-nickgoodwin-october-2010.pdf. Accessed November 27, 2013.

46. Cukor P, Baer L, Willis BS, et al. Use of videophones and low-cost standard telephone lines to provide a social presence in telepsychiatry. Telemed J. 1998;4:313-321.

47. Allen R. Teams without walls. Clin Med. 2009;9:4-5.

48. Royal College of Physicians. Care Closer to Home: Narrative Report. London: RCP; 2012.

49. Rialle V, Ollivet C, Guigui C, Hervé C. What do family caregivers of Alzheimer's disease patients desire in smart home technologies? Contrasted results of a wide survey. Methods Inf Med. 2008;47: 63-69.

50. Giger JT. Perspectives of Informal Caregivers on Using in-Home Technology to Monitor Activities of Persons with Serious Mental Illness [doctoral thesis]. (MO): University of Missouri; 2010.

51. Zulman DM, Piette JD, Jenchura E, Asch SM, Rosland AM. Facilitating out-of-home caregiving through health information technology: survey of informal caregivers' current practices, interests and perceived barriers. J Med Internet Res. 2013;15:e123.

52. Wallis J. Dorset Telecare Project: Review of Project Pilot. Final Report: 2008.
53. Keeping-Burke L, Purden M, Frasure-Smith N, Cossette S, McCarthey F, Amsel R. Evaluation of the psychological effects of a telehealth program for caregivers of coronary artery bypass graft (CABG) surgery patients. Can J Cardiol. 2011;27:S346.

54. Lind L. Towards Effortless Use of Information Technology in Home Healthcare with a Networked Digital Pen [dissertation]. Linköping, Sweden: Linköping University; 2006.

55. Soar J, Seo Y. Health and aged care enabled by information technology. Ann NY Acad Sci. 2007;114:154-161.

56. Magnusson L, Hanson E. Supporting frail older people and their family carers at home using information and communication technology: cost analysis. J Adv Nurs. 2005;51:645-657.

57. Bank AL, Argüelles S, Rubert M, Eusdorfer C, Czaja SJ. The value of telephone support groups among ethnically diverse caregivers of people with dementia. Gerontologist. 2006;46:134-138.

58. Topo P, Jylha M, Laine J. Can the telephone-using abilities of people with dementia be promoted? An evaluation of a simple-to-use telephone. Technol Dis. 2002;14:3-13.

59. Topo P. Technology studies to meet the needs of people with dementia and their caregivers. J Appl Gerontol. 2009;28:15-37.

60. Marineau ML. Special populations: telehealth advanced practice nursing: the lived experiences of individuals with acute infections transitioning in the home. Nurs Forum. 2007;42:196-208.

61. Wright LK, Bennet G, Gramling L. Telecommunication interventions for caregivers of elders with dementia. Adv Nurs Sci. 1998;20: 76-88.

62. Glueckauf RL, Noel LT. Telehealth and family caregiving: developments in research, education, policy, and practice. In: Toseland RW, Haigler DH, Monahan DJ, editors. Education and Support Programs for Caregivers. Heidelberg: Springer; 2011.

63. Hanson J, Percival J, Aldred H, Brownsell S, Hawley M. Attitudes to telecare among older people, professional care workers and informal carers: a preventative strategy or crisis management? Univ Access Inf Soc. 2007;6:193-205.

64. Winterton R, Warburton J. Models of care for socially older rural carers: barriers and implications. Rural Remote Health. 2011;11:1678.

65. Van Ast P, Larson A. Supporting rural carers through telehealth. Rural Remote Health. 2007;7:634

66. Marziali E, Garcia LJ. Dementia caregivers' response to 2 Internet-based intervention programs. Am J Alzheimers Dis Other Demen. 2011;26: $36-43$.

67. Asteljoki S. Assessing Perspectives of Needs and Values for e-Service Development of Renal Patients and Their Next of Kin [doctoral thesis]. Kerava (Finland): Laurea University of Applied Sciences.

68. Sävenstedt S, Sandman PO, Zingmark K. The duality in using information and communication technology in elder care. JAdv Nursing. 2006;56: 17-25.

69. Lutz BJ, Young ME. Rethinking intervention strategies in stroke family caregiving. Rehabil Nurs. 2010;35:152-160.

70. Buckley KM, Tran BQ, Prandoni CM. Receptiveness, use and acceptance of telehealth by caregivers of stroke patients in the home. Online J Issues Nurs. 2004;9:9.

71. Johnstone B, Kidd L, Wengstrom Y, Kearney N. An evaluation of the use of telehealth within palliative care settings across Scotland. Palliat Med. 2012;26:152-161.

72. Alwan M, Dalal S, Mack D, et al. Impact of monitoring technology in assisted living: outcome pilot. IEEE Trans Inf Technol Biomed. 2006;10: 192-198.

73. Lutz BJ, Chumbler NR, Lyles T, Hoffman N, Kobb R. Testing a hometelehealth programme for US veterans recovering from stroke and their family caregivers. Disabil Rehabil. 2009;5:402-409.

74. Li KF. Smart home technology for telemedicine and emergency management. J Ambient Intell Human Comput. 2013;4:535-546.

75. Quint RD, Chesterman E, Crain LS, Winkleby M, Boyce T. Home care for ventilator-dependent children. Psychosocial impact on the family. Am J Dis Child. 1990;144:1238-1241. 
76. Lehoux P. Patients' perspectives on high-tech home care: a qualitative enquiry into user-friendliness of four technologies. BMC Health Serv Res. 2004;4:28.

77. Istepanian R, Jovanov E, Zhang YT. Introduction to the special section on M-Health: beyond seamless mobility and global wireless health-care connectivity. IEEE Trans Inf Technol Biomed. 2004;8:405-414.

78. Rietdijk R, App B, Togher L, Power E. Supporting family members of people with traumatic brain injury using telehealth: a systematic review. J Rehabil Med. 2012;44:913-921.

79. Greenhalgh T, Proctor R, Wherton J, Sugarhood P, Shaw S. The organising vision for telehealth and telecare: discourse analysis. $B M J$ Open. 2012;2:e01574.
80. Hensel BK, Demiris G, Courtney KL. Defining obtrusiveness in home telehealth technologies: a conceptual framework. J Am Med Inform Assoc. 2006;13:428-431.

81. Sanders C, Rogers A, Bowen R, et al. Exploring barriers to participation and adoption of telehealth and telecare with the Whole System Demonstrator trial: a qualitative trial. BMC Health Serv Res. 2012;12:220.

82. Orwell G. Nineteen Eighty-Four. Penguin. 1979.

\section{Publish your work in this journal}

Smart Homecare Technology and TeleHealth is an international, peer-reviewed, open access online journal publishing original research, reviews, editorials and commentaries on the application of technology to support people and patients at home and in assisted living centers to optimize healthcare and managemen resources. Specific topics in the journal include: Development and application of devices within the home and embedded in appliances; Healthcare provider communication and education tools; and drug ordering and adherence. The manuscript management system is completely online and includes a very quick and fair peer-review system, which is all easy to use. Visit http://www.dovepress.com/ testimonials.php to read real quotes from published authors.

Submit your manuscript here: http://www.dovepress.com/smart-homecare-technology-and-telehealth-journal 